\title{
ENSINO DE HISTÓRIA MEDIADO PELA METODOLOGIA DA CONSTRUÇÃO DE MAPA CONCEITUAL
}

\author{
CURIITIBA/PR JUNHO/2018 \\ Cleber Bianchessi - uninter - cleberbian@yahoo.com.br \\ Ademir Aparecido Pinhelli Mendes - Uninter - ademir.m@uninter.com \\ Tipo: Relato de Experiência Inovadora (EI) \\ Categoria: Métodos e Tecnologias \\ Setor Educacional: EDUCAÇÃO MÉDIA E TECNOLÓGICA
}

\begin{abstract}
RESUMO
O artigo discorre a experiência realizada com a ferramenta Mapa Conceitual elaborada por Novak e aborda a dinâmica da construção do conhecimento mediante a Aprendizagem Significativa de Ausubel (1980). Objetiva-se diagnosticar qual a interferência dos Mapas Conceituais no processo do ensino de História pelos alunos do Ensino Médio, bem como compreender os benefícios propiciados pelos mapas conceituais ao aluno na possibilidade de atribuir ao conhecimento forma colaborativa. Ademais, objetiva-se propor uma dinâmica interativa auxiliada pelos mapas conceituais e analisar benefícios para aprendizagem significativa do aluno. Inicia-se com a metodologia da sala de aula invertida introduzindo o préstimo do software livre CmapTools e na web por intermédio do aplicativo Sway. Nesse contexto, relata-se a prática da construção do conhecimento numa conotação mais participativa entre os estudantes, mediante atribuição de significado a cada etapa ou momento da aprendizagem. O seu ápice ocorre com a apresentação em equipes os assuntos debatidos, bem como a análise coletiva e a significativa dos conceitos. Ressalta-se no artigo a experiência observada e o embasamento teórico na construção do Mapa Conceitual com as adequadas habilidades desenvolvidas mediante a prática instrutiva no percurso do ensino e da aprendizagem no cotidiano escolar. Registra-se a realização da prática pedagógica exercida pelo professor de História e a manifestação reflexiva e significativa sobre as atividades empreendidas na construção do conhecimento. Destaca-se, conclusivamente, que esta ferramenta disponibiliza várias potencialidades e algumas dificuldades ou resistências estudantis quais se destacaram no decorrer do processo construtivo do Mapa Conceitual. O relato de experiência ocorre com alunos do $3^{\circ}$ ano do ensino médio, do período matutino na disciplina de História, pertencentes a um colégio público estadual localizado na cidade de Curitiba PR e no qual um dos autores deste relato atua como docente.
\end{abstract}

Palavras-chave: Ensino de História. Mapa Conceitual. Metodologias Ativas. 


\section{INTRODUÇÃo}

Pretende-se, neste relato de experiência, apresentar a inserção dos mapas conceituais como ferramentas auxiliares nas práticas educativas cotidianas da disciplina de História, bem como alternativa pertinente à estratégia de avaliação. O intuito deste relato é demonstrar as diversas potencialidades dos mapas conceituais como ferramenta facilitadora da aprendizagem significativa e do exercício da prática de referido instrumento. Os Mapas Conceituais são esquemas conceituais representados nas relações hierarquizadas entre conceitos e originaram-se na década de 70. Eles foram criados pelo físico norte americano Joseph D. Novak influenciado pela Teoria da Aprendizagem Significativa de David Ausubel (1980).

No assunto, destacam-se as contribuições fundamentais ofertadas pela Teoria da Aprendizagem Significativa de Ausubel (1980) a qual aponta que o conhecimento transferido ao discente no cotidiano escolar deve ser utilizado na aprendizagem de novos conteúdos, solucionando problemas presentes no ambiente escolar ou até mesmo além dos muros escolares. Dessa forma, a aprendizagem significativa contribui para mudanças estruturais cognitivas do conhecimento. Para permitir isso, utiliza-se da construção do Mapa Conceitual por meio do softwareCmapTools, com especificidades interpretativas dos instrumentos didáticos organizados e reflexivos do conhecimento.

O relato de experiência, ademais, apresenta argumentações teóricas que fundamentam a dinâmica ativa do encadeamento de ensino e de aprendizagem referenciando a Teoria da Aprendizagem Significativa (AUSUBEL, 1980) e a constituição de Mapas Conceituais (NOVAK, 2008) como ferramentas didáticas e pedagógicas que auxiliam nas práticas educativas. Na sequência, registra-se passo a passo a construção dos Mapas Conceituais de forma interativa e colaborativa. No entendimento de Moreira (2010, p. 06), os "Mapas conceituais foram desenvolvidos para promover a aprendizagem significativa". Por fim, apresentam-se as contribuições dos discentes na elaboração das diversas atividades e, por conseguinte, os resultados alcançados com uma verificação dos Mapas Conceituais construídos pelos alunos buscando sinais da aprendizagem significativa.

\section{APRENDIZAGEM SIGNIFICATIVA DE AUSUBEL}

$\mathrm{Na}$ prática da construção do conhecimento de História, as destacadas aprendizagens significativas dos alunos, como salientado por Ausubel (1980), decorre quando novas informações surgem e se relaciona de forma não arbitrária de modo substantivo e não literal com conhecimentos expressivos da disposição ordenada do indivíduo. 
Destacando-se o conhecimento já pertencente ao discente, os mapas conceituais podem ser nominados como ferramenta auxiliar para avaliar por intermédio dos quais se detecta o que já existe, relevando-se de forma integral os princípios da aprendizagem significativa de Ausubel, por meio da qual ocorre a apreensão da aprendizagem significativa pertencente à sua teoria. $O$ sujeito deste processo já traz conhecimentos acerca dos conteúdos abordados. Ademais, importante não menosprezar os conhecimentos prévios para que não sejam produzidos ou assimilados conhecimentos inadequados.

Compreende-se que um novo conhecimento pode ser construído quando, por meio da aprendizagem significativa, for acompanhado e relacionado de outro conhecimento preexistente. Este processo pode ser construído apenas quando tiver manifestação de interesse do sujeito para a aprendizagem. Concomitantemente se fazem necessários 0 planejamento do professor, que de maneira potencialmente significativa valora a origem e o contexto do discente, bem como a inserção social do objeto a ser apreendido.

A essência do processo de aprendizagem significativa é que as ideias expressas simbolicamente são relacionadas às informações previamente adquiridas pelo aluno através de uma relação não arbitrária e substantiva (AUSUBEL, NOVAK e HANESIAN, 1980, p. 34).

Dessa forma, é possível apreender diversas informações novas, em especial, destacamse os conceitos compreendidos de modo relevante e significativo ao interagir de modo substancial com o conhecimento oriundo do aprendiz e que dele tomou posse por meio da inclusão na organização do conhecimento pelo sujeito, mediante funcionamento de forma interativa entre ambas. Dessa maneira, também ocorre a valorização dos conteúdos levados para a sala de aula e, fruindo-se deles, pode contribuir com o processo de construção da erudição. Nesta perspectiva, a mediação dos mapas conceituais representa instrumentos adequados ao monitoramento das perspectivas de aprendizagem, propiciando práticas docentes centradas na mediação pedagógica por se tornarem representações alheias aos esquemas cognitivos. Eles se tornam um instrumento na integração de diferentes conceitos.

Por intermédio da Teoria da Aprendizagem Significativa são estabelecidas conceituações iniciais de aprendizagem, o que permite reorganizar o cognitivo, ou seja, os novos processos com os quais a hodierna informação se relaciona com determinados aspectos dos conhecimentos trazidos pelo estudante e podem transformá-lo de modo significativo, ao atribuir sentido nas relações dos novos conhecimentos e dos conceitos pertencentes ao discente. 
sua vez, incluem a presença de muitos alunos de motivação, prontidão e aptidões desiguais; as dificuldades de comunicação entre professor e aluno; as características particulares de cada disciplina que está sendo ensinada; e as características das idades dos alunos (AUSUBEL; NOVAK; HANESIAN, 1980, p. 5).

Determinados fatores de compreensão afetiva, social ou cognitiva reorganizam-se na concepção centrada da aprendizagem significativa, de maneira a permitir sentido no estabelecimento das relações entre os novos conhecimentos construídos e os que já existem no aprendiz. Este processo no estabelecimento de vínculos ocorre por meio das descobertas e da recepção dos conteúdos aprendidos pelo aluno na forma final ou pelas descobertas conceituais antes da interação com a Teoria da Aprendizagem Significativa.

Este processo de elaboração permite aos discentes estabelecer as vinculações entre os conhecimentos precedentes e adquiridos com a prática da sala de aula invertida e as novas temáticas e criando maiores oportunidades de integração. As concepções estão normalmente incluídas nos círculos, retângulos ou noutros atributos, e as apresentações constam de duas ou mais abstrações unidas por palavras de ligação, concebendo uniformidade significativa. Geralmente os mapas conceituais oportunizam sua interpretação e leitura numa evolução do alto para baixo.

Nesse contexto, torna-se perceptível visualmente a conceituação e suas relações de forma hierarquizada entre os agentes envolvidos de forma que é importante para identificar as possíveis mudanças estruturais do conhecimento dos alunos. O processo de instrução constitui uma estratégia que facilita tanto a aprendizagem significativa como atividades de conceituar, às quais devem ser construídos de forma colaborativa entre os discentes. Torna-se, portanto, respeitável ferramenta no auxílio dos procedimentos de construção e de assimilação do conhecimento significativo no ensino de História.

\section{EXPERIÊNCIA COM MAPA CONCEITUAL NO ENSINO DE HISTÓRIA}

No percurso do procedimento no ensino de História e da aprendizagem significativa, os Mapas Conceituais tornam-se instrumentos auxiliares na demonstração das relações hierarquizadas dos conceitos que estão sendo transmitidos em uma aula ou aprendidos pelo discente de forma autônoma.

\footnotetext{
Os mapas conceituais são ferramentas gráficas para organizar e representar o conhecimento. Eles incluem conceitos, geralmente encerrados em círculos ou caixas de algum tipo, e relações entre conceitos indicados por uma linha de conexão que liga dois conceitos. As palavras na linha, referidas como palavras de ligação ou frases de ligação, especificam a relação entre os dois conceitos. Definimos o conceito como uma regularidade percebida em eventos ou objetos, ou registros de eventos ou objetos, designados por um rótulo (NOVAK e CAÑAS, 2008).
}

O software livre CmapTools foi a opção para a elaboração dos Mapas Conceituais com 
os discentes pois, além de fácil manuseio, com ele é possível gravar a locução permitindo aos usuários iniciar, pausar ou reproduzir a gravação. Também é permitida a explicação, passo a passo, da explanação ou reproduzir dinamicamente a qualquer instante todos os movimentos permitidos pela ferramenta com a permissão de retomar a qualquer momento cada etapa do processo de construção. Este software disponibiliza diversas oportunidades de intercâmbios e interação entre os usuários e os pesquisadores. O mapa conceitual é ao mesmo tempo simples, mas também elegantemente complexo com significados profundos. Desta forma, mapear conceitos proporciona aos estudantes a aprender e a criar novos conhecimentos, capazes de proporcionar melhores condições de forma estruturada e autônoma.

No que concerne à importância da utilização desta ferramenta, é possível observar que este software facilita aos estudantes e, porventura outros usuários de outras idades, a alteração e a modificação dos mapas conceituais facilita a compreensão e a análise do interlocutor, bem como processar com maestria o texto representado em forma esquemática. Nessa seara, é totalmente possível vincular as diversas qualidades dos mapas conceituais aos benefícios tecnológicos. Dessa forma, torna-se viável disponibilizá-los na web para que qualquer pessoa interessada consiga acessá-los para obter conhecimento dos conceitos registrados no mapa conceitual (NOVAK E CAÑAS, 2008).

Dessa forma, intermediar o processo de instrução e de aprendizado com mapas conceituais representa um caminho alternativo para diversificar as práticas pedagógicas dos docentes de História no ambiente escolar, propiciando sua autonomia e sua responsabilidade estudantil ao alcançar e conquistar no seu percurso formativo, bem como ensinar e aprender. Com isso, possibilita-se ao discente alcançar novos lugares e construir novos saberes que permitem gerar criticidade e comprometimento com um aprender significativo e com saberes que podem ser inseridos na abrangência das dimensões pedagógicas e didáticas, ao refletir concepções diferenciadas para a educação.

Para o estudo, utilizou-se o Sway (https://sway.com/my) que é um aplicativo do Office 365 o qual proporciona contribuir com o esclarecimento e com a expressão coletiva das ideias, mediante a utilização de uma tela interativa alicerçada na web. Os mecanismos de design do Sway contribuem para a produção de forma agilizada e de fácil compreensão no âmbito da educação, com designs atrativos e interativos, por meio de imagens, textos, gráficos, declarações diversas, vídeos, mapas e outros. Outrossim, com o Sway é possível produzir uma destacada aparência de criação e pode ser compartilhado concomitantemente com os alunos ou outros interessados sendo 
suficiente enviar o link. Este aplicativo funciona como uma ferramenta autoral com capacidade mais eficaz do que utilizar os slides, pois é possível fazer publicações de fotografias, apresentações, de forma a disponibilizar conteúdos visualmente agradáveis.

Por isso, propõe-se apresentar aspectos de análise da prática pedagógica do ensino de História auxiliada pelos mapas conceituais construídos pelos discentes do $3^{\circ}$ ano, do ensino médio do período matutino, de um colégio público estadual localizado na cidade de Curitiba PR.

A disciplina de História começou a ser ministrada por este profissional em referido estabelecimento de ensino, em abril de 2017, mas a utilização dos mapas conceituais só ocorreu no segundo semestre do decorrente ano como estratégia de proporcionar uma aprendizagem mais dinâmica e próxima dos anseios dos alunos diante das diversas tecnologias presentes no cotidiano escolar. A dinâmica do processo para construir o mapa conceitual com a sucedida experiência dos alunos do ensino médio percorreu os seguintes estágios:

a) Dinâmica da sala de aula invertida, sendo possível instigar a imaginação, previamente, com o estudo individualizado do tema proposto. Na sala de aula, o aluno torna-se conhecedor do assunto, transformando-se num sujeito autônomo e iniciando a interação aluno-professor, mediante a elucidação de suas dúvidas e possibilitando a construção do conhecimento com as atividades de forma colaborativa;

b) Foram apresentados vídeos explicativos e exemplos para a construção de mapas conceituais, tais como: definição dos termos a ser utilizada, estruturação do mapa conceitual, elementos fundamentais que são necessários serem incluídos, preposições ou palavras de ligação, etc.;

c) Organização da turma em grupos por ordem numérica do registro de classe em quantidade de dez alunos que se dedicam a estudar, em cada grupo, um tema de forma individualizada;

d) Leitura individualizada dos conteúdos propostos exercitando continuamente a sala de aula invertida ao discutir, na sequência, o tema em sala de aula e com os demais componentes da classe, permitindo a seleção individual dos conceitos e exercício da troca de experiências de aprendizagem e de compreensões distintas com a contribuição dos colegas;

e) Após o desenvolvimento do conteúdo específico, os alunos foram orientados a 
registrar e hierarquizar os conceitos estudados de forma individualizada. Construir seu mapa conceitual permite registrar os significados atribuídos à vinculação dos conceitos sob orientação do professor quando demandado;

f) Sequencialmente, é oportunizado o trabalho em grupos com temas afins definidos anteriormente e exercitando o trabalho em equipe bem como discutir de forma colaborativa as diferentes compreensões e interpretações sobre o mesmo tema. Como resultado, estes alunos constroem um único mapa conceitual registrando em uma cartolina e permitindo uma maior visibilidade e compreensão dos conceitos resultantes desta interação;

g) Em outra aula, os alunos são deslocados para o laboratório de informática e orientados a registrarem este mapa no software livre denominado CmapTools. Esta parte da atividade também é construída coletivamente e sob a orientação do professor;

h) Ao finalizarem, os alunos são orientados a encaminhar para o e-mail do professor o resultado final deste mapa conceitual. Por sua vez, o professor disponibiliza todos os mapas conceituais no https://sway.com/, por meio do qual os alunos terão acesso a todos os mapas conceituais construídos pelos grupos e, por consequência, os diversos temas estudados;

i) Para finalizar o processo, cada grupo apresenta o mapa conceitual para toda turma de alunos constituindo unidade dos conteúdos estudados, enriquecendo a aprendizagem ao relacionarem conceitualmente com os assuntos estudos e disponibilizados ao coletivo. Apresentam as conclusões na sala de aula amparados pelo mapa conceitual, pelo https://sway.com/ e também auxiliados pela TV Pendrive.

j) Para evitar situações desagradáveis, nas quais alguns alunos constroem a tarefa e outros não participam, - mas incluem seus nomes no trabalho-, o critério de apresentação foi determinar que todos do grupo participassem da apresentação para toda turma.

k) A avaliação ocorre de forma processual e participativa na qual o aluno é convidado, no momento seguinte, a dissertar e a registrar os conteúdos, auxiliado pelo mapa conceitual como forma de avaliação final. Portanto, se permitiu ao aluno exercer a compreensão autônoma e individual, interagir com o coletivo e enriquecer sua aprendizagem na compreensão interativa dos conteúdos propostos.

I) Finaliza-se atribuindo uma nota numérica para cada etapa da construção do mapa 
conceitual e posteriormente divulgada aos alunos com respectivos feedbacks coletivos e individualizados.

Envoltos pela teoria da aprendizagem significativa, conclui-se que a dinâmica do processo de construção dos mapas conceituais propiciou aos discentes estabelecer relações entre os conhecimentos que foram construídos previamente de forma autônoma com os novos conteúdos apresentados no ambiente escolar, surgindo diversas possibilidades com os conceitos interconectados. Dessa forma, é possível contribuir de modo eficiente na construção do conhecimento pelo aprendiz, consoante Moreira (2010) descreve que

\footnotetext{
Na aprendizagem significativa o novo conheci mento nunca é internalizado de maneira literal, porque no momento em que passa a ter significado para o aprendiz entra em cena o componente idiossincrático da significação. Aprender significativamente implica atribuir significados e estes têm sempre componentes pessoais. Aprendizagem sem atribuição de significados pessoais, sem relação com o conhecimento preexistente, é mecânica, não significativa. Na aprendizagem mecânica, o novo conhecimento é armazenado de maneira arbitrária e literal na mente do indivíduo. O que não significa que esse conhecimento seja armazenado em um vácuo cognitivo, mas sim que ele não interage significativamente com a estrutura cognitiva preexistente, não adquire significados. Durante um certo período de tempo, a pessoa é inclusive capaz de reproduzir o que foi aprendido mecanicamente, mas não significa nada para ela. (MOREIRA, 2010, p. 6).
}

Sendo assim, a utilização dos mapas conceituais permite aos alunos assimilar os conteúdos por meio de um instrumento inovador no processo do aprendizado com perspectiva que os situam e fazem perceber como sujeito no ambiente escolar. Favorece, dessa forma, organizar suas ideias e estreitar laços com o acesso a construção de saberes diferentes daqueles evidenciados inicialmente, pois os significados são geralmente particulares. Dessa maneira, o ensino de História, manifestado na aprendizagem de conteúdos mediante representação esquemática do mapa conceitual, estimula e propicia a capacidade de criar relações que se constituem e em condições para o surgimento de novas etapas de aprendizagem.

\section{CONSIDERAÇÕES FINAIS}

Considera-se que os mapas conceituais proporcionaram uma dinâmica de ótima aceitação pelos alunos, os quais questiona, inclusive, a utilização do método em outras disciplinas por considerarem facilitadores da aprendizagem. Identificou-se que ocorria utilização inadequada dos mapas conceituais por outros professores. A sua correta interpretação possibilita internalizar de maneira empolgante, instigante e efetiva dos mapas conceituais, pois se torna criticamente um potencial instrumento das práticas pedagógicas e facilitadoras no processo de instrução e de aprendizado. 
Perante o exposto, com o auxílio dos mapas conceituais na construção do conhecimento, observou-se que o aluno desenvolve habilidades e competências como a memorização, aspectos comparativos e diferenciados, funções de atenção, abstração na autonomia seletiva dos conteúdos considerados expressivos no estabelecimento das conexões entre eles e com os conhecimentos trazidos externamente na elaboração de uma síntese gráfica das proposições. Evidencia-se, neste processo de aprendizagem, a manifestação do aluno pela associação dos conceitos e dos atributos de suas relações, traduzindo de forma organizada a estrutura cognitiva ao revelar concepções, conhecimento dos conteúdos e criatividade na elaboração gráfica dos conceitos ao propiciar consciência dos avanços obtidos bem como, eventualmente, das dificuldades identificadas.

Diante disso, expressar-se publicamente e trabalhar numa equipe, com divergências de opiniões e nem sempre com convivência amena no ambiente escolar e direcionado pelo mapa conceitual, foi uma dificuldade manifestada por alguns alunos por ser primeira oportunidade de construção significativa e coletiva do conhecimento. Os mapas conceituais foram apresentados, e os temas debatidos, na perspectiva de discussão e sugestão provenientes das apresentações, na qual os discentes têm oportunidade de expor sobre o objeto estudado e apresentar a evolução na compreensão dos conceitos e de suas relações.

A análise desta dinâmica permitiu aos estudantes atingir estas considerações, pois se apoderou da sua autonomia e da sua comparação de aprendizagem e resultados observados no desempenho. No decorrer do processo construtivo, na percepção do envolvimento dos alunos e observação do cotidiano escolar na sala de aula, bem como pelos comentários espontâneos dos alunos e com a possibilidade de dinamizar o processo do ensino e aprendizado ao utilizar os mapas conceituais, estes podem ser relacionados com a sala de aula invertida e o uso das novas tecnologias.

Exploram-se movimentos com diversos critérios analíticos permitindo avaliação do processo de ensino e de aprendizagem ultrapassando o mecanicismo e permitindo experiências inovadoras. As orientações prestadas resultaram em aspectos potencializados e animadores pelas proporções que foi possível observar bem como para enfatizar as possibilidades teóricas e conceituais. A averiguação empreendida apresentou-se como uma valiosa ferramenta auxiliar de trabalho no exercício das práticas educativas para o docente de História e muito profícua ao discente na assimilação dos conteúdos e autonomia na construção do conhecimento proposto neste processo de aprendizagem. 
Recomenda-se que mais dinâmicas sejam aplicadas em turmas com perfis semelhantes para averiguar o potencial dos mapas conceituais na metodologia de ensino e aprendizagem, pois se considera, em demasia, positivo o estudo que permitiu alcançar os resultados almejados e perceptíveis na experiência aqui relatada, por intermédio do uso de mapas conceituais no ensino História.

\section{REFERÊNCIAS}

AUSUBEL. David P. NOVAL, Joseph D.; HANESIAN, Helen. Psicologia Educacional. Editora: Editora Interamericana, RJ. 2ª edição, 1980.

MORENO, Lídia Ruiz et al. Mapa conceitual: Ensaiando critérios de análise. Ciência \& Educação, vol. 13, no 3, 2007.

MOREIRA, Marco Antônio. Mapas Conceituais E Aprendizagem Significativa. São Paulo: Editora Centauro, 2010.

NOVAK, Joseph D. CAÑAS, Alberto J. Joseph D. Novak e Alberto J. Cañas. Os Mapas Conceituais de Teoria Subjacente e como construí-los e usá-los. Relatório Técnico IHMC CmapTools. Institute for Human and Machine Cognition, 2008, disponível em: < https://cmap.ihmc.us/docs/theory-of-concept-maps>. Acesso em 10 mai.2018. 